\title{
Gamma Oscillations Induced by Kainate Receptor Activation in the Entorhinal Cortex In Vitro
}

\author{
Mark 0. Cunningham, ${ }^{1}$ Ceri H. Davies, ${ }^{2}$ Eberhard H. Buhl, ${ }^{1}$ Nancy Kopell, ${ }^{3}$ and Miles A. Whittington ${ }^{1}$ \\ ${ }^{1}$ School of Biomedical Sciences, Worsley Building, University of Leeds, Leeds, LS2 9NQ, United Kingdom, ${ }^{2}$ GlaxoSmithKline, Harlow, Essex, CM19 5AW, \\ United Kingdom, and ${ }^{3}$ Department of Mathematics, Boston University, Boston, Massachusetts 02115
}

Gamma frequency $(30-80 \mathrm{~Hz})$ oscillations are recordable from human and rodent entorhinal cortex. A number of mechanisms used by neuronal networks to generate such oscillations in the hippocampus have been characterized. However, it is as yet unclear as to whether these mechanisms apply to other anatomically disparate brain regions. Here we show that the medial entorhinal cortex ( $\mathrm{mEC}$ ) in isolation in vitro generates gamma frequency oscillations in response to kainate receptor agonists. Oscillations had the same horizontal and laminar spatiotemporal distribution as seen in vivo and in the isolated whole-brain preparation. Oscillations occurred in the absence of input from the hippocampal formation and did not spread to lateral entorhinal regions. Pharmacological similarities existed between oscillations in the hippocampus and $\mathrm{mEC}$ in that the latter were also sensitive to $\mathrm{GABA}_{\mathrm{A}}$ receptor blockade, barbiturates, $\mathrm{AMPA}$ receptor blockade, and reduction in gap junctional conductance. Stellate and pyramidal neuron recordings revealed a large GABAergic input consisting of gamma frequency IPSP trains. Fast spiking interneurons in the superficial mEC generated action potentials at gamma frequencies phase locked to the local field. Stellate cells also demonstrated a subthreshold membrane potential oscillation at theta frequencies that was temporally correlated with a theta-frequency modulation in field gamma power. Disruption in this stellate theta frequency oscillation by the hyperpolarisation activated current $\left(I_{\mathrm{h}}\right)$ blocker ZD7288 also disrupted theta modulation of field gamma frequency oscillations. We propose that similar cellular and network mechanisms to those seen in the hippocampus generate and modulate persistent gamma oscillations in the entorhinal cortex.

Key words: gamma oscillation; kainate; interneuron; theta; stellate cell; cortex

\section{Introduction}

Cortical gamma band $(30-80 \mathrm{~Hz})$ oscillations are thought to grant large ensembles of neurons the ability to engage in associative binding, in particular during processing of incoming sensory signals (Gray et al., 1989; Singer and Gray, 1995) (for review, see Verala et al., 2001). Thus, gamma activity has been recorded in sensorimotor (Murthy and Fetz, 1996), auditory (Barth and MacDonald, 1996), and visual cortices (Roelfsema et al., 1997). Gamma frequency oscillations have been reported in the entorhinal cortex (EC) of humans during wakefulness (Hirai et al., 1999; Uchida et al., 2001), as well as in rodents in vivo (Charpak et al., 1995; Chrobak and Buzsáki, 1998) and in an isolated whole-brain preparation (van Der Linden et al., 1999; Dickson et al., 2000b).

The EC occupies a unique position in the temporal lobe, in that it acts as an interface between neocortical regions and the cornu ammonuis, as well as other associated limbic structures such as the subiculum and dentate gyrus (Van Hoesen, 1982; Witter et al., 1989; Burwell and Witter, 2002). Superficial neurons of the EC supply the main neocortical input to the hippocampus via the perforant pathway (Steward and Scoville, 1976; Witter

Received June 20, 2003; revised July 17, 2003; accepted Aug. 13, 2003.

This work was supported by the Medical Research Council (United Kingdom) and The National Institutes of Health.

Correspondence should be addressed to M. A. Whittington, School of Biomedical Sciences, The Worsley Building, University of Leeds, Leeds LS2 9NQ, UK. E-mail: m.a.whittington@leeds.ac.uk.

Copyright $\odot 2003$ Society for Neuroscience $\quad$ 0270-6474/03/239761-09\$15.00/0 and Groenewegen, 1984; Amaral and Witter, 1989), whereas the deep layer neurons receive output from the hippocampus via CA1 and the subiculum (Harris et al., 2001; Naber et al., 2001). In this respect, the EC occupies a pivotal position in the process of gating information flow along the neo-archicortical axis. Hence, the EC is assumed to act as a supermodal associational cortical region, in which inputs from a number of sensory areas can assemble (Van Hoesen, 1982; Amaral and Witter, 1989; Witter et al., 1989) and engage in a functional interplay of sensory information with the hippocampus (Fernandez et al., 1999; Fell et al., 2001). The importance of the EC is further emphasized by the fact that it is an early and selective site of pathological changes that occur in disorders of memory function such as Alzhemier's disease (Van Hoesen, 1982; Hyman et al., 1984; Van Hoesen et al., 1986; Braak and Braak, 1991) and schizophrenia (Beckmann and Senitz, 2002).

Gamma oscillations have been described in a number of in vitro slice preparations. In a number of these, metabotropic receptor activation has induced this activity (Whittington et al., 1995; Fisahn et al., 1998) or application of nanomolar concentrations of kainate (Hájos et al., 2000; Hormuzdi et al., 2001). However, attempts to elicit gamma activity in an in vitro preparation of the EC with application of the metabotropic cholinergic agonist carbachol occasionally resulted in the generation of epileptiform activity (Dickson and Alonso, 1997; Gloveli et al., 1999). Here we present data that demonstrates that the activation of 
kainate receptors can generate persistent gamma activity in vitro in the EC. This activity was associated with sparse activation of principal cell soma but large-scale phasic interneuronal output. Population gamma frequency activity was associated with trains of IPSPs in a similar manner to that seen in models of hippocampal gamma oscillation.

Parts of this paper have been published previously in abstract form (Cunningham et al., 2002a,b).

\section{Materials and Methods}

Preparation of slices. Transverse EC hippocampal slices $(450 \mu \mathrm{m})$ were prepared from adult Sprague Dawley rats, anesthetized with inhaled isoflurance, immediately followed by an intramuscular injection of ketamine $(\geq 100 \mathrm{mg} / \mathrm{kg})$ and xylazine $(\geq 10 \mathrm{mg} / \mathrm{kg})$. Animals were intracardically perfused with $\sim 50 \mathrm{ml}$ of modified artificial CSF (ACSF), which was composed of the following (in $\mathrm{mM}$ ): 252 sucrose, $3 \mathrm{KCl}, 1.25$ $\mathrm{NaH}_{2} \mathrm{PO}_{4}, 24 \mathrm{NaHCO}_{3}, 2 \mathrm{MgSO}_{4}, 2 \mathrm{CaCl}_{2}$, and 10 glucose. All salts were obtained from $\mathrm{BDH}$ Chemicals (Poole, UK). The brain was removed and submerged in cold $\left(4-5^{\circ} \mathrm{C}\right)$ ACSF during dissection, and horizontal slices were cut using a Campden Instruments (Loughborough, UK) vibroslice. Slices were then transferred either to a holding chamber or directly to a recording chamber. Here, they were maintained at $34^{\circ} \mathrm{C}$ at the interface between a continuous stream ( $1.2 \mathrm{ml} / \mathrm{min}$ ) of ACSF (in mM: $126 \mathrm{NaCl}, 3$ $\mathrm{KCl}, 1.25 \mathrm{NaH}_{2} \mathrm{PO}_{4}, 24 \mathrm{NaHCO}_{3}, 2 \mathrm{MgSO}_{4}, 2 \mathrm{CaCl}_{2}$, and 10 glucose) and warm, moist carbogen gas $\left(95 \% \mathrm{O}_{2}-5 \% \mathrm{CO}_{2}\right)$. Slices were permitted to equilibrate for $45 \mathrm{~min}$ before any recordings commenced.

Drugs. All drugs were bath applied at known concentrations: kainic acid (2S,3S,4R)-carboxy-4-(1methylethenyl)-3-pyrrolidineacetic acid), 200-400 nм; NBQX (2,3-dioxo-6-nitro-1,2,3,4-tetrehydrobenzo[f] qui noxaline-7-sulfonamide), $20 \mu \mathrm{M}$; carbachol, 20-50 $\mu \mathrm{M}$; domoic acid, ([2S-[2a,3b,4b $(1 \mathrm{Z}, 3 \mathrm{E}, 5 \mathrm{R}]]$,-2 -carboxy-4-(-5-carboxy-1-methyl-1,3hexadienyl)-3-pyrrolidineacetic acid), $100 \mathrm{~nm}$; bicuculline methochloride, $2 \mu \mathrm{M}$; and ZD7288 (4-ethylphenylamino-1,2-dimethyl-6methylaminopyridinium chloride), $10 \mu \mathrm{M}$. All were obtained from Tocris Cookson (Bristol, UK). Pentobarbital $(20 \mu \mathrm{M})$ and carbenoxenlone $(100 \mu \mathrm{M})$ were obtained from Sigma (Poole, UK).

Recording, data acquisition, and analysis. Extracellular recordings electrodes were pulled from borosilicate glass (Harvard Apparatus, Kent, $\mathrm{UK}$ ) filled with ACSF and had resistances in the range of $2-5 \mathrm{M} \Omega$. For the purpose of intracellular recordings, electrodes were pulled from borosilicate glass filled with $\mathrm{KCH}_{3} \mathrm{SO}_{4}$ and had resistances in the range of 70-130 $\mathrm{M} \Omega$. Three types of neuron were recorded from in the entorhinal cortex, each identified by the following specific electrophysiological parameters. Stellate cells had pronounced sag observed with hyperpolarizing current step, with action potentials present on rebound depolarization. Longduration depolarizing current steps $(500-800 \mathrm{msec}$ ) revealed action potentials of stellates cells had a fast afterhyperpolarization (fAHP), which was followed by a depolarizing after potential (DAP), and action potential had half-widths $>1 \mathrm{msec}$. There was also accommodation of action potentials. During tonic depolarization, stellate cells exhibited a subthreshold membrane oscillation. Pyramidal cells displayed little or no sag in response to hyperpolarizing current, and a rebound depolarization was not observed. No subthreshold membrane oscillation was apparent. Depolarizing current revealed that action potentials of pyramidal cells displayed an fAHP but no DAP and had half-widths $<1.5 \mathrm{msec}$. Action potential accommodation was also observed (van Der Linden and Lopes de Silva, 1998). Maximum firing frequencies on current injection were $>400 \mathrm{~Hz}$, there was no action potential accommodation, and action potential half-widths were $<0.6 \mathrm{msec}$. Peak frequency and power values were obtained from power spectra generated with Fourier analysis in the Axograph software package (Axon Instruments, Foster City, CA). Power for a given frequency band was determined as the area under the peak in the power spectra between 20 and $80 \mathrm{~Hz}$ for gamma frequency oscillations. All values are given as mean \pm SE. Power spectra were constructed offline from digitized data (digitization frequency, $10 \mathrm{kHz}$ ) using a $60 \mathrm{sec}$ epoch of recorded activity. MatLab (MathWorks, Natick, MA) was used to generate spectrograms. The kinetics of IPSPs were measured using
A

i

Superficial Deep
Control

miny
B

i

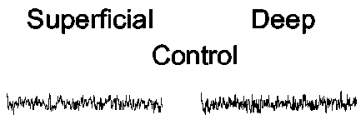

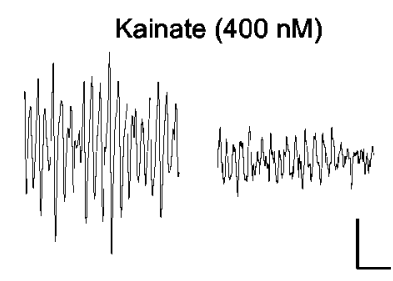

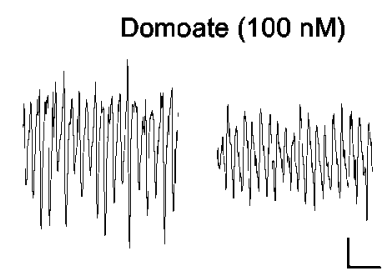

ii

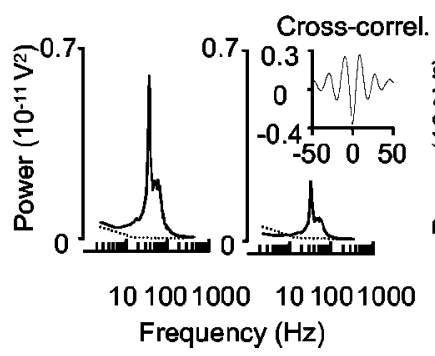

Figure 1. Application of nanomolar concentrations of kainate receptor agonists induced persistent network oscillations in the $\mathrm{mEC}$ in vitro. A, Perfusion of kainate $(400 \mathrm{~nm})$ generated fast oscillations in the gamma range in the superficial and deep layers of the $\mathrm{mEC}$. Field recordings in $\mathrm{Ai}$ demonstrate extracellular recordings from superficial and deep $\mathrm{mEC}$ during control and $60 \mathrm{~min}$ after the initial application of kainate. Aii, Pooled power spectra $(n=36)$ for $60 \mathrm{sec}$ epochs of field recording before (dashed line) and after (solid line) kainate application in superficial (left graph) and deep (right graph) mEC. Bi, Addition of the more potent kainate receptor agonist domoate $(100 \mathrm{~nm})$ also produced fast oscillations in the gamma range. Bii, Pooled power spectra of the signals before and after the application of domoate for superficial and deep layers $(n=5)$. The inset graphs in both power spectra are cross-correlograms of the superficial and deep traces shown in $A i$ and Bi. Calibration: $A i, B i, 50 \mu \mathrm{V}, 100 \mathrm{msec}$.

MiniAnalysis (Jaejin Software, Leonia, NJ), and >200 IPSPs were obtained per slice and pooled for additional analysis.

\section{Results}

Kainate receptor agonists induced gamma activity in the medial EC

When slices of EC were bath perfused with nanomolar concentrations of kainic acid $(200-400 \mathrm{nM})$, rhythmic $(50-200 \mu \mathrm{V})$ field activity was observed in all slices studied $(n=36)$ (Fig. 1A). Activity in the superficial and deep layers had a mean frequency of $46.4 \pm 1.9$ and $45.4 \pm 2.0 \mathrm{~Hz}$, respectively, whereas the mean area power was $622.0 \pm 116.6$ and $215.9 \pm 43.6 \mu \mathrm{V}^{2} \mathrm{sec}^{-1}$, respectively. In all cases, the power of the oscillation was significantly greater in superficial layers than with that in the deep layers $(p<0.001)$ (Fig. 1A), although there was no significant difference in mean frequencies $(p<0.1)$. The activity between superficial and deep layers of the EC was in anti-phase (Fig. $1 A$, inset). Once initiated, the network activity was stable for many hours $(\sim 4-5 \mathrm{hr})$. In addition, the more potent kainate receptor agonist domoic acid (domoate) (100 nM) was also able to elicit network activity in both layers of the EC $(n=5)($ Fig. $1 B)$. The activity in 
superficial and deep layers had a mean frequency of $48.3 \pm 3.9$ and $48.3 \pm 3.5 \mathrm{~Hz}(n=5)$ and a mean area power of $828.4 \pm$ 383.8 and $415.0 \pm 171.3 \mu \mathrm{V}^{2} \mathrm{sec}^{-1}$, respectively. A crosscorrelogram of the activity produced by domoate revealed, in agreement with kainate experiments, that a sharp $180^{\circ}$ phase reversal was seen when comparing deep with superficial layers (see Fig. 3).

\section{Spatial profile of gamma activity in the EC}

Previously, Fisahn (1999) has demonstrated that the bath application of kainate can generate gamma activity in the hippocampus in vitro. When $400 \mathrm{~nm}$ kainate was bath applied to the intact slice preparation (containing both entorhinal cortex and hippocampus), gamma activity was observed in stratum pyramidale in both CA 3 and CA 1 in this present study. The gamma activity had a significantly lower mean frequency [CA3, $32.6 \pm 1.8 \mathrm{~Hz}$; CA1, $33.7 \pm 1.1 \mathrm{~Hz} ; n=9 ; p<0.05$ compared with medial entorhinal cortex (mEC) data above]. The EC and the hippocampus have extensive and robust reciprocal connections (Witter et al., 1986). Therefore, to determine whether the EC was capable of generating gamma activity independent of the hippocampus, we performed a number of microlesions. Control activity in the EC was recorded before subsequent microlesions. The control activity had a mean area power of $537.0 \pm 122.5$ (superficial) and $310.7 \pm 68.6 \mu \mathrm{V}^{2} \mathrm{sec}^{-1}$ (deep). Lesion of area CA3 from the rest of the slice produced no significant change in mean area power in the mEC (superficial, $408.6 \pm 118.0 \mu \mathrm{V}^{2} \mathrm{sec}^{-1}$; deep, $232.6 \pm$ $77.6 \mu \mathrm{V}^{2} \mathrm{sec}^{-1} ; p>0.05$ compared with prelesion values; $n=6$ ). Additional lesion of area CA1 from the mEC recording sites had no significant effect on mean area power (superficial, $371.2 \pm$ 107.1; deep, $238.8 \pm 83.8 \mu \mathrm{V}^{2} \mathrm{sec}^{-1} ; p>0.05 ; n=6$; data not shown).

In vivo and whole-brain studies also demonstrated that entorhinal gamma activity was spatially localized across the horizontal plane of the mEC (van Der Linden et al., 1999). To test this in vitro, a reference electrode was orientated at the most medial portion of the $\mathrm{mEC}$, and a second electrode was then moved in 50 $\mu \mathrm{m}$ steps toward the lateral EC. In the superficial layers, the amplitude and area power of gamma activity was consistent across $300 \mu \mathrm{m}$ of the medial portion of the EC and sharply diminished on reaching the lateral EC (Fig. $2 \mathrm{~A}$ ). In the deep layers, gamma activity peaked in the medial portion and slowly diminished as the electrode was moved laterally (Fig. 2A). No change in peak frequency of kainate-induced oscillation was seen along the longitudinal axis of EC in either deep or superficial layers. Direct comparison of power in the gamma frequency range between $\mathrm{mEC}$ and lateral EC showed a significant reduction in oscillations in the lateral part of EC $(p<0.05 ; n=6)$ (Fig. $2 B)$.

In the isolated guinea pig whole-brain preparation (Chrobak and Buzsáki, 1998; van Der Linden et al., 1999; Dickson et al., 2000b), gamma oscillations were shown to have a marked phase reversal through the laminas. We tested this by placing one reference electrode in the subcortical white matter of the angular bundle and a second electrode close and perpendicular to the reference electrode in $100 \mu \mathrm{m}$ steps toward the pia. Around level of the perisomatic region (i.e., between layers II and III), a distinct phase reversal was observed (Fig. $3 A, B$ ). The maximal area power of gamma was also observed around the site of phase reversal, in layer III ( $\left.1130.5 \pm 174.6 \mu \mathrm{V}^{2} \mathrm{sec}^{-1} ; n=22\right)$. To ascertain whether this phase shift was simply attributable to a polarity change of the extracellular field or a genuine phase difference between gamma generators in deep and superficial layers, we performed joint field and intracellular IPSP train measurements.
A
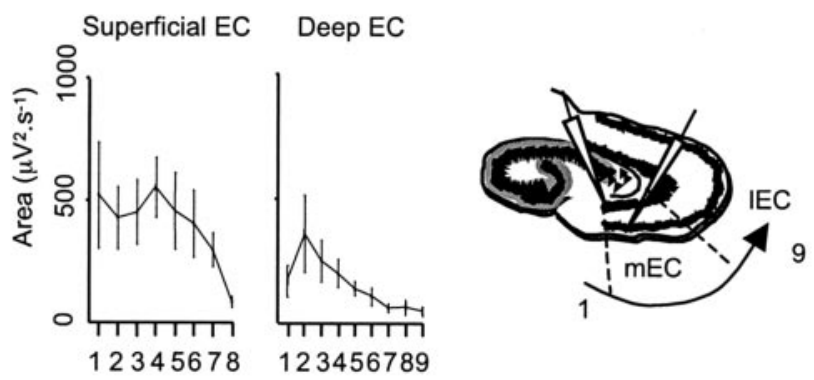

B

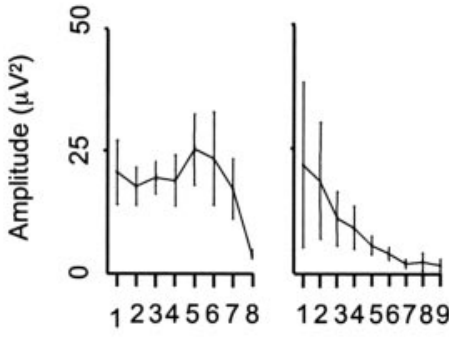

Superficial

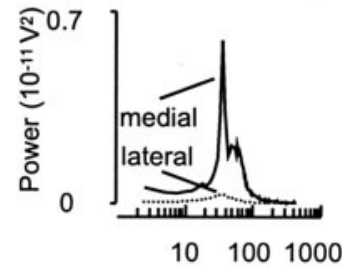

Frequency $(\mathrm{Hz})$
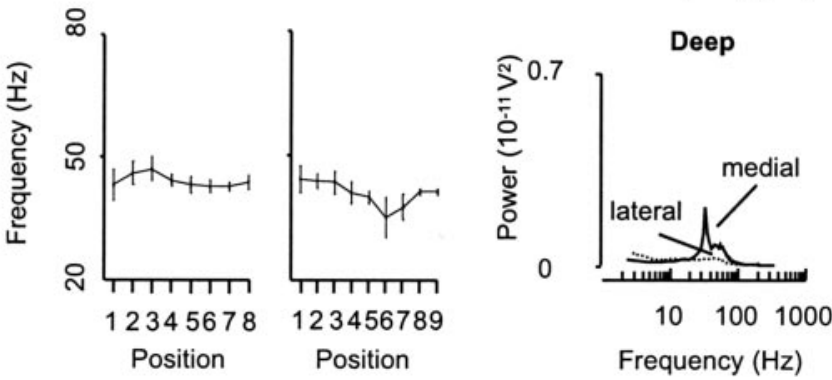

Figure 2. Lateral profile of gamma activity across superficial and deep layers. Electrode was moved in $50 \mu \mathrm{m}$ steps from a reference position at the most medial portion of the mEC as illustrated in the diagram. $A$, Graphs show pooled data $(n=6)$ for area power (top two graphs) and peak power and frequency (bottom two graphs) across superficial and deep layers of the $\mathrm{mEC}$. As the recording electrode is moved across the lamina to a more lateral position, the power of the activity significantly diminished. IEC, Lateral EC. B, Pooled power spectra $(n=6)$ illustrating that there was little gamma activity observed in the lateral EC (dashed line) during the application of kainate when compared with the $\mathrm{MEC}$ (solid line).

Intracellular events in layer III pyramidal neurons and extracellular activity in layer II were found to be in-phase (Fig. 4A), whereas intracellular events in layer III pyramidal neurons and field activity in layer III were in anti-phase (Fig. 4B). Intracellular events in layer II stellate cells and field activity in layer III were also in anti-phase (Fig. 4C). Thus, principal neurons on either side of the layer in which the field phase shift was seen share the same temporal pattern of inhibitory drive despite changes in the phase of the field (see Discussion).

\section{GABAergic and glutamatergic pharmacology of gamma} activity in the $\mathrm{mEC}$

Gamma activity in the hippocampus is critically dependent on the rhythmic synchronous output of populations of interneurons (Whittington et al., 1995; Fisahn et al., 1998). To test whether this hypothesis also held for the entorhinal cortex, we first reduced fast GABAergic transmission. After inducing gamma activity with kainate, coapplication of a low concentration of bicuculline $(2 \mu \mathrm{M})$ resulted in the virtual abolition of the population gamma 
A

B

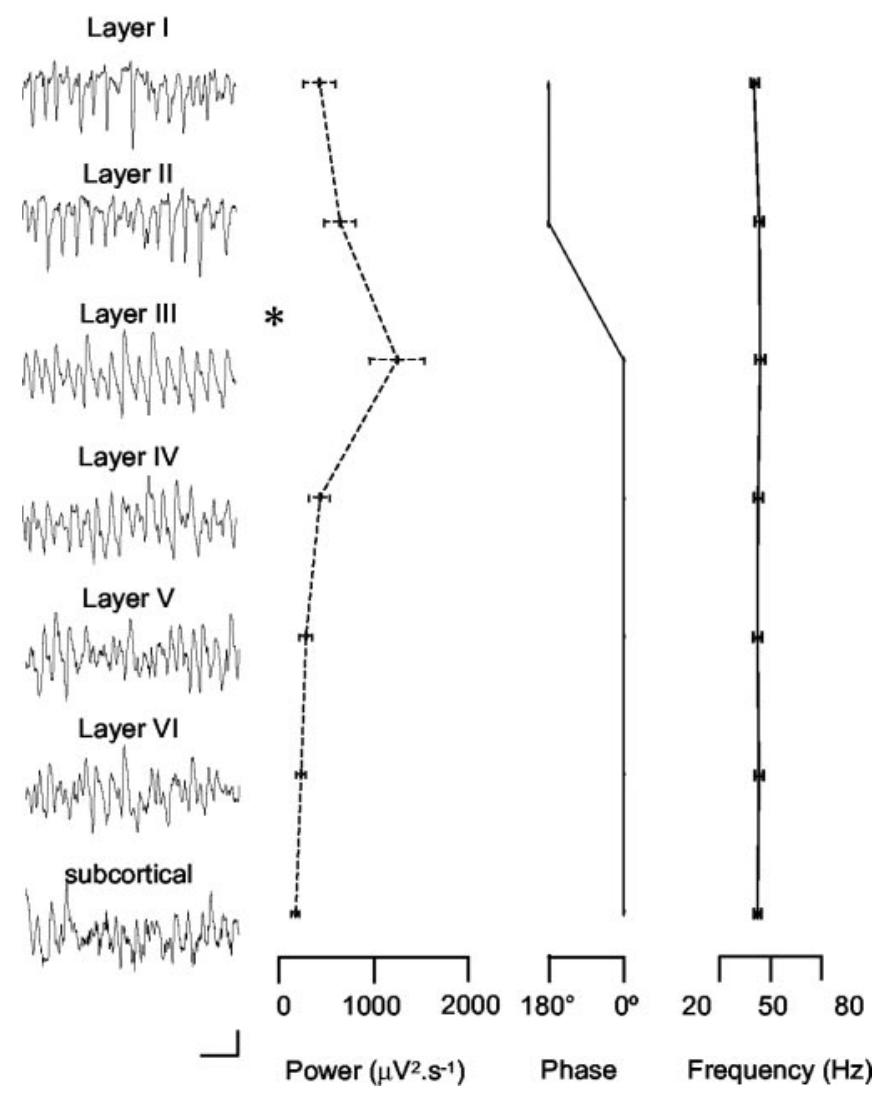

Figure 3. Laminar profile of gamma activity in the $\mathrm{mEC}$. Profile was obtained by placing one electrode as a reference in the subcortical white matter, and a second electrode was then moved in steps of $100 \mu \mathrm{m}$ across the $\mathrm{mEC}$ laminas. A, Field recordings illustrating gamma activity across all layers of the $\mathrm{mEC}$ in one experiment. Note the phase change marked with an asterisk, which occurred in the region between layers II and III. B, Graphs showing pooled data $(n=12)$ for power, phase, and frequency. Note that layer III exhibits the highest gamma activity and that the phase shift is confirmed; in addition, the frequency of the activity was consistent across all layers. Calibration: $A, 50 \mu V, 50 \mathrm{msec}$.

activity $(n=7)$ (Fig. $5 A$ ). Prolongation of the decay kinetics of $\mathrm{GABA}_{\mathrm{A}}$ receptor-mediated IPSPs has been shown to have a marked effect on gamma oscillations driven by tonic interneuronal excitation but much less of an effect when phasic excitation is required (Whittington et al., 2000). Pentobarbital $(20 \mu \mathrm{M})(n=$ 6) (Fig. $5 B)$ produced a small but significant reduction $(p<$ 0.001 ) in the peak frequency of gamma activity (superficial: control, $45.8 \pm 2.6$; pentobarbital, $37.4 \pm 2.8$; washout, $45.4 \pm 2.4$ Hz; deep: control, $43.7 \pm 2.6$; pentobarbital, $34.9 \pm 2.6$; washout, $44.8 \pm 2.8 \mathrm{~Hz}$ ). Fast phasic glutamatergic transmission has been demonstrated to influence persistent gamma activity in hippocampal and neocortical slices (Buhl et al., 1998; Fisahn et al., 1998). Thus, we investigated the possible involvement of this mechanism in mEC by blocking AMPA receptors. Addition of SYM $2206(20 \mu \mathrm{M} ; n=3)$, a potent noncompetitive AMPA receptor antagonist (Li et al., 1999; Behr et al., 2001), significantly reduced gamma frequency activity in both the superficial and deep layers $(p<0.05)$ (Fig. $6 A)$. In superficial layers only, this near abolition of activity in the gamma band was accompanied by a small but significant increase in activity at lower frequencies (4-12 Hz range) (peak frequency: control vs SYM 2206, $44.8 \pm$ 2.5 vs $11.6 \pm 1.6 \mathrm{~Hz} ; p<0.001$ ). In a subsequent set of experiments, the application of the mixed AMPA/kainate receptor an-
A

IPSPs LIII

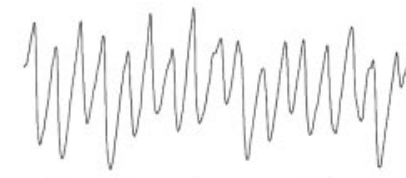

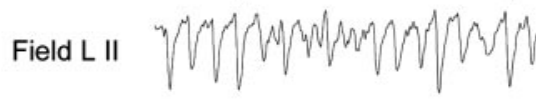

L

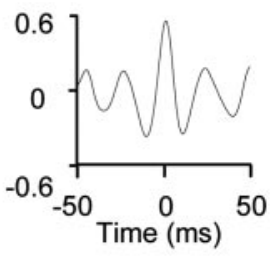

B

IPSPs LIII

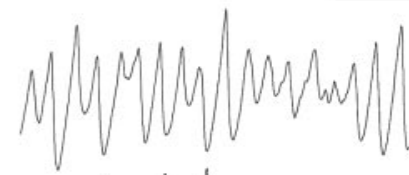

Field L III
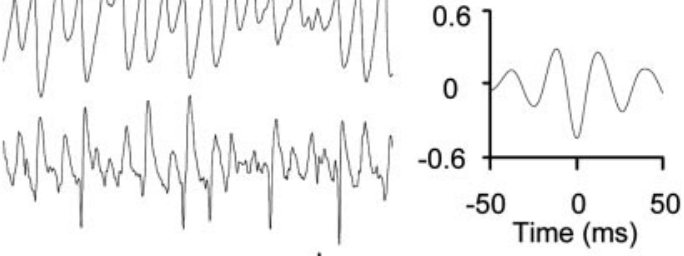

C

IPSPs LII

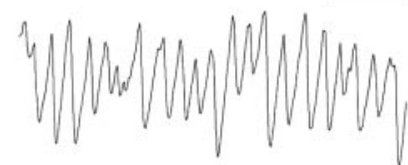

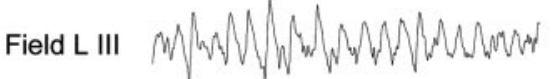

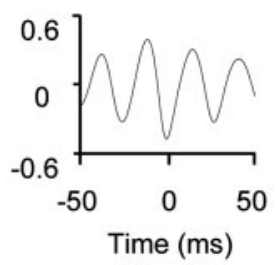

Figure 4. Origin of the phase reversal of gamma activity observed in the mEC. A, Top trace, Intracellular recording of rhythmic IPSP activity in a layer III (LIII) pyramidal cell during ongoing gamma oscillation; the cell was depolarized to $-40 \mathrm{mV}$ by injection of current through the recording electrode. Bottom trace, Simultaneous extracellular field recording in layer II (LII), i.e., across the phase reversal point illustrated in Figure 4. Graph shows pooled cross-correlogram $(n=6)$ of concurrently recorded field and intracellular IPSP data. The activity was in-phase. $B$, IPSPs again recorded from layer III pyramidal neuron (membrane potential, $-40 \mathrm{mV}$ ), with concurrent field recordings of gamma activity in layer III, i.e., at the same side of the phase reversal point illustrated in Figure 4. Pooled cross-correlogram $(n=6)$ demonstrates that the IPSPs and field are $180^{\circ}$ out of phase. C, IPSPs recorded from a layer II stellate neuron depolarized to $-40 \mathrm{mV}$; the bottom trace is a concurrent field recording from layer III of the mEC. Pooled cross-correlogram $(n=6)$ shows the activity to be $180^{\circ}$ out of phase. Calibration: $A-C$, top trace, $1 \mathrm{mV}, 100 \mathrm{msec}$; bottom trace, $50 \mu \mathrm{V}, 100 \mathrm{msec}$.

tagonist NBQX (20 mm; $n=3)$, abolished all rhythmic activity in both layers (Fig. $6 B$ ).

The precise timing of phasic excitatory inputs to interneurons during gamma oscillations in the hippocampus has been proposed to involve gap junctions between principal cell axons (Traub et al., 2000). In the mEC, application of the gap junction blocker carbenoxolone (100 $\mu \mathrm{M})$ significantly $(p<0.05 ; n=6)$ reduced gamma power in both the superficial (control vs drug, $\left.399.9 \pm 97.2 \mathrm{vs} 115.1 \pm 38.7 \mu \mathrm{V}^{2} \mathrm{sec}^{-1}\right)$ and deep $(56.9 \pm 10.1 \mathrm{vs}$ $14.3 \pm 5.1 \mu \mathrm{V}^{2} \mathrm{sec}^{-1}$ ) layers (data not shown).

\section{Characterization of cellular and synaptic behavior during gamma activity in the $\mathrm{mEC}$}

Using sharp microelectrodes, we examined the intrinsic and synaptic properties of both principal excitatory neurons and putative, fast spiking inhibitory interneurons. When stellate neurons in layer II and pyramidal neurons in layer III were recorded at depolarized holding potentials (at least $-40 \mathrm{mV}$ ) (Fig. 4), trains of large-amplitude IPSPs were seen $(8.3 \pm 0.2 \mathrm{mV} ; n=5871$ IPSPs from eight neurons). Spectral analysis demonstrated a peak in the gamma range (layer II vs layer III, $42.3 \pm 2.3$ vs $37.3 \pm 1.1$ $\mathrm{Hz}$ ). With no holding current applied, stellate neurons in layer II and pyramidal neurons in layer III fired spontaneous action po- 
A

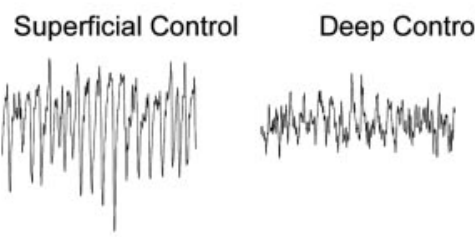

Bicuculline $(2 \mu \mathrm{M})$
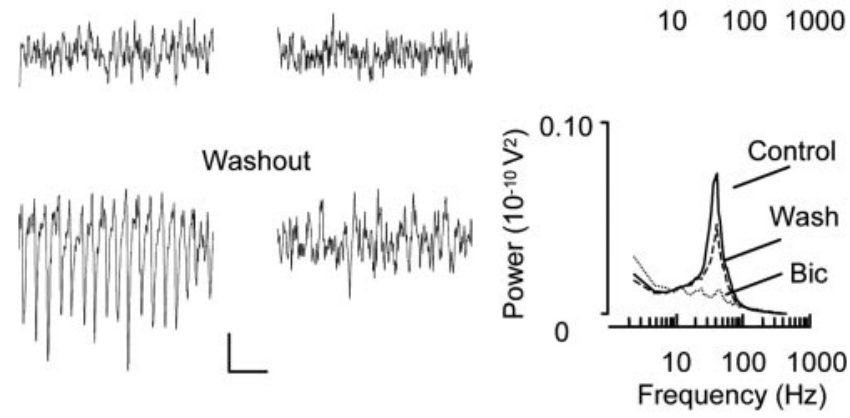

B
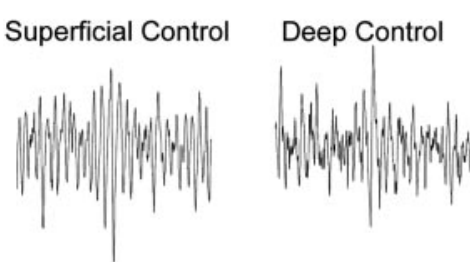

Pentobarbital $(20 \mu \mathrm{M})$
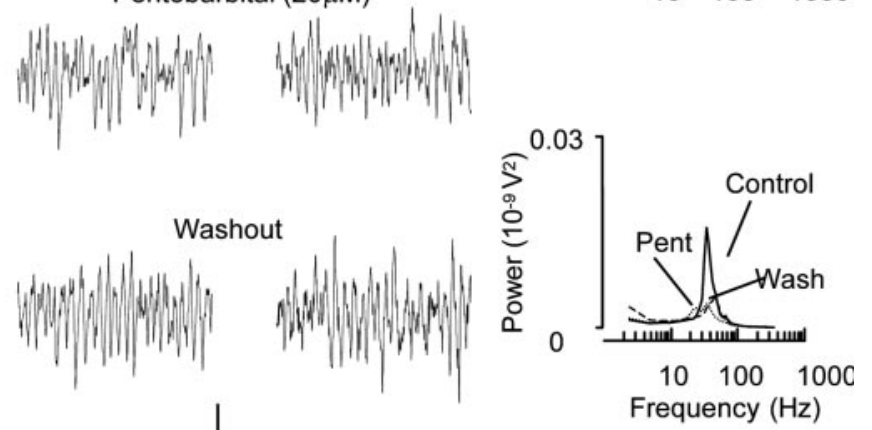

Figure 5. Gamma frequency oscillations in the $\mathrm{mEC}$ were critically dependent on $\mathrm{GABA}_{\mathrm{A}}$ receptor-mediated activity. $A$, The $G A B A_{A}$ receptor antagonist bicuculline (Bic; $2 \mu \mathrm{m}$ ) virtually abolished gamma activity in both superficial and deep layers of the $\mathrm{mEC}$. Activity was restored on washout (Wash) of the drug. Power spectrums located in the right panel illustrate pooled results for both layers $(n=7)$. B, Traces show control activity from superficial and deep mEC. Application of pentobarbital (Pent; $20 \mu \mathrm{M}$ ) caused the power of the activity, as well as a slowing of the frequency of the activity. This reduction in both superficial and deep layers was highly significant $(p<0.001)$, and the effect was reversible on washout. Power spectra located in the right panel demonstrate pooled power spectra $(n=6)$. Calibration: $A, B, 50 \mu V$, $100 \mathrm{msec}$.

tentials, with significantly different $(p<0.05)$ mean frequencies of $0.7 \pm 0.1$ and $5.0 \pm 0.6 \mathrm{~Hz}(n=6)$ (Fig. 7A), respectively. When the membrane potential of neurons was adjusted to close to the reversal potential of IPSPs (at least $-70 \mathrm{mV} ; n=7$ ), smallamplitude EPSPs $(1.4 \pm 0.01 \mathrm{mV} ; n=5900)$ were observed. Analysis of these events demonstrated that they were generated over a faster frequency range than concurrent stellate-pyramidal cell output (stellate vs pyramid, $7.6 \pm 0.6$ vs $11.8 \pm 0.7 \mathrm{~Hz} ; p<$ 0.05 ) (Fig. $7 B, C$ ). Recordings from fast spiking interneurons lo-
A

Superficial Control + SYM $2206(20 \mu M)$
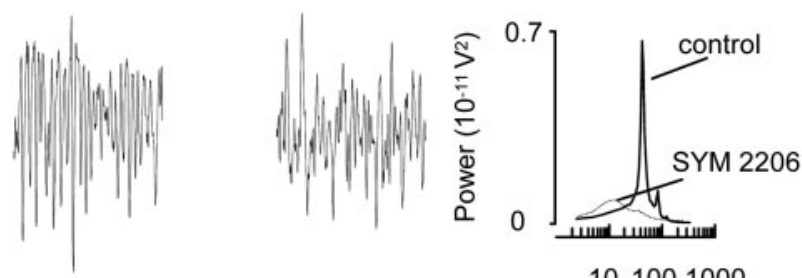

101001000

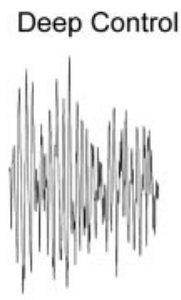

+ SYM $2206(20 \mu \mathrm{M})$
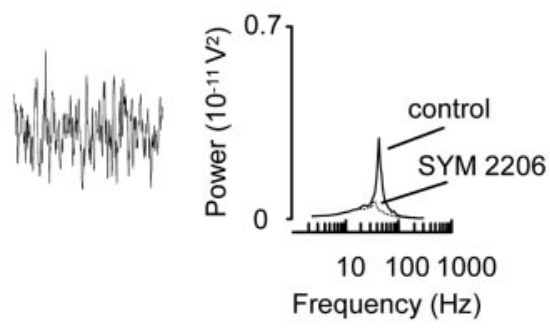

B

Superficial Control $\quad+$ NBQX $(20 \mu M)$
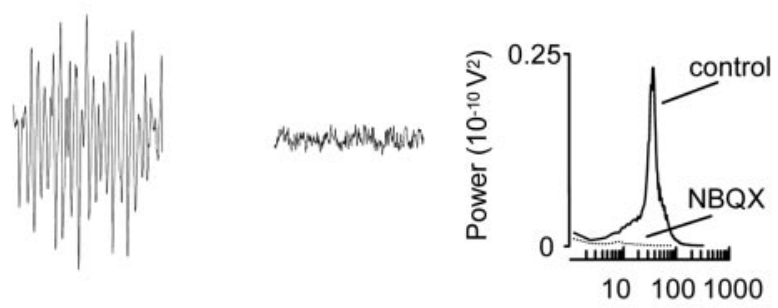

Deep Control

$+\operatorname{NBQX}(20 \mu \mathrm{M})$
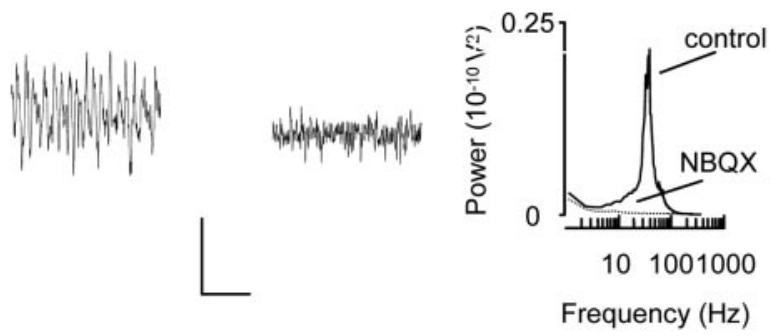

Figure 6. Action of AMPA receptor antagonists on $\mathrm{mEC}$ gamma activity. A, Example traces showing the action of SYM $2206(20 \mu \mathrm{m})$ on field gamma oscillations in superficial and deep $\mathrm{mEC}$. Whereas gamma activity was abolished in deep layers, in the superficial layers, addition of the drug abolished activity in the gamma band but revealed a small peak in the theta range. Power spectra illustrate the pooled data from these experiments $(n=3)$. $B$, Control field recordings show gamma activity in superficial and deep layers of the $\mathrm{mEC}$ before and after addition of NBQX. Pooled power spectra $(n=3)$ are shown in the right panel. Calibration: $A, B$, $50 \mu \mathrm{V}, 100 \mathrm{msec}$.

cated in layer II $(n=3)$ revealed that, during field gamma oscillations, these cells generated action potentials in the gamma range $(45.1 \pm 2.8 \mathrm{~Hz})$. These interneurons received significantly larger EPSPs at faster frequencies than in the two principal neuron types studied. However, EPSPs were still present in these cells 
A
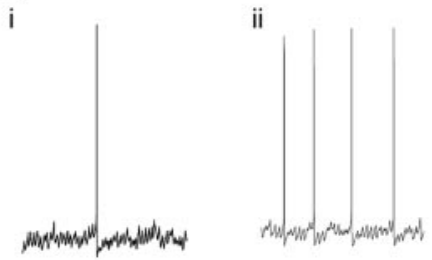

iii

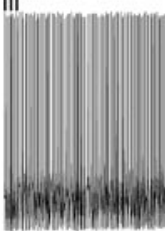

B

i

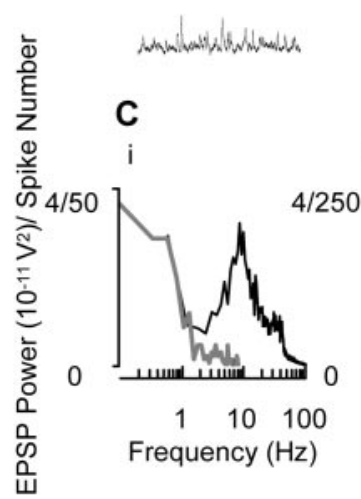

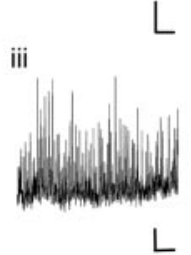

iii

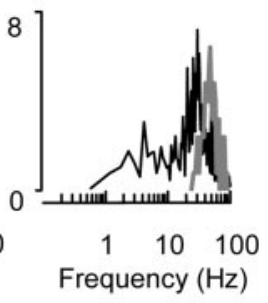

Figure 7. Pattern of action potential generation in three major cell types in the superficial $\mathrm{mEC}$ during gamma activity. A, Intracellular recordings from layer II stellate neuron ( $i$ ), layer III pyramidal neuron (ii), and a layer II fast spiking interneuron (iii) during kainate-induced field gamma frequency oscillations. $B$, Recordings of EPSP trains in each cell type injected with hyperpolarizing current to keep membrane potential at $-70 \mathrm{mV}$. Examples of such recordings from a layer II stellate, layer III pyramid, and layer II interneuron are illustrated in i-iii. C, Combined action potential frequency histograms and EPSP power spectra illustrate the frequency of action potentials and EPSPs in an example from each cell type. Cell firing frequencies are shown as the gray lines, and EPSPs power spectra are the black lines. Calibration: $A, 10 \mathrm{mV}$, $250 \mathrm{msec} ; B, 2 \mathrm{mV}, 250 \mathrm{msec}$.

at lower frequencies than their output (EPSP frequency was $29.3 \pm 2.8 \mathrm{~Hz}$; compare with action potential frequency above).

\section{The origin of theta frequency modulation of field gamma oscillations}

Unlike in vivo and isolated whole-brain superficial mEC recordings, no clear peak at theta frequency was seen in power spectra (Fig. 1). However, the amplitude of field gamma activity in the superficial mEC (layers II and III) was strongly modulated at theta frequencies throughout kainate application (modulation frequency, $3.2 \pm 0.2 \mathrm{~Hz} ; n=12$ ) (Fig. $8 A, B$ ). In contrast, as observed in vivo (Chrobak and Buzsáki, 1998), field gamma frequency activity in the deep layers demonstrated no such clear modulation (Fig. 8C). This frequency modulation was significantly different from the pattern of synaptic excitation see in either principal cell type (3.2 vs $7.6 \mathrm{~Hz} ; 3.2$ vs $11.8 \mathrm{~Hz} ; p<0.001$ ) (Fig. 7).

It has been shown previously that stellate cells in the EC have theta frequency subthreshold membrane potential oscillations (Alonso and Llinás, 1989; Alonso and Llinás, 1993; Jones, 1994). In this model, stellate cells demonstrated a subthreshold theta frequency membrane potential oscillation of $3.2 \pm 0.1 \mathrm{~Hz}(n=$ 11) with a fixed phase relationship with the modulated concurrent field recordings $(5.9 \pm 1.1 \mathrm{msec} ; n=11)$. To investigate whether this behavior in these cells was responsible for the observed modulation of gamma frequency oscillations, we recorded
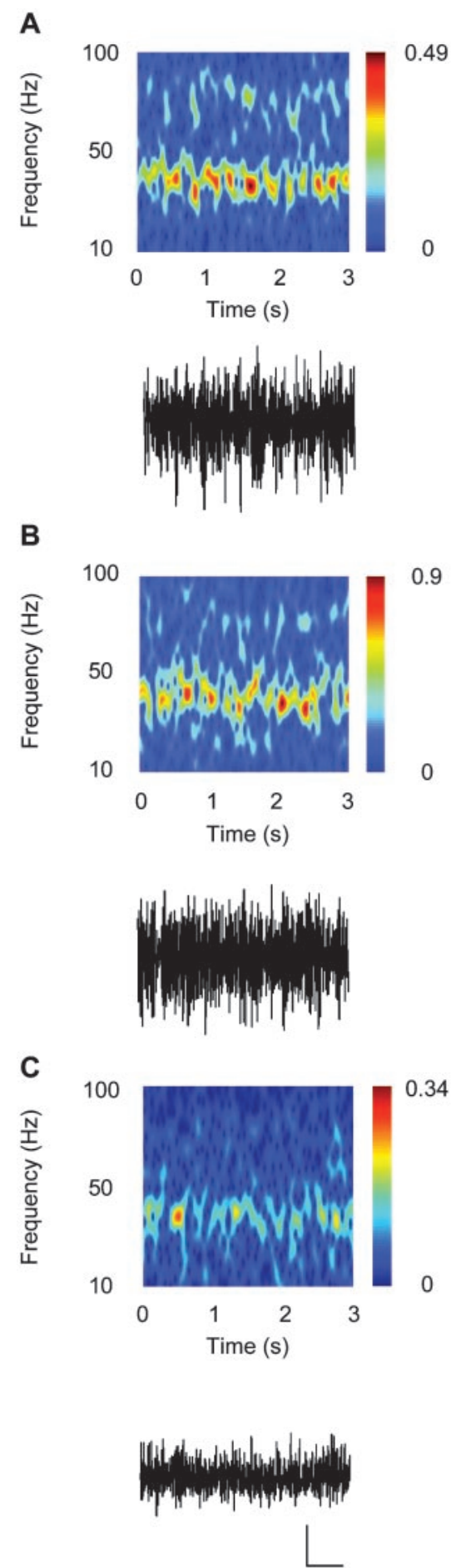

Figure 8. Theta frequency modulation of field gamma frequency oscillations in superficial layers. $A$, Spectrogram of a 3 sec period of field gamma activity in layer II of the $\mathrm{mEC}$. Note the theta frequency occurrence of "hotspots" of power in the gamma band. Bottom trace is raw data trace of the activity shown in spectrogram. $B$, Spectrogram of a 3 sec period of field gamma activity in layer III of the $\mathrm{mEC}$. Again, bottom trace is raw data trace of the activity analyzed. $C$, Spectrogram illustrating relative paucity of theta frequency modulation of field gamma oscillation power in the deep mEC. Bottom trace is raw data. Calibration: $A-C, 50 \mu \mathrm{V}, 500 \mathrm{msec}$. Note different scales on the spectrograms

from stellate cells concurrently with superficial EC field recordings in the presence and absence of $10 \mu \mathrm{M}$ ZD7288. The subthreshold membrane potential oscillation has been proposed to be, in part, mediated by the action of a hyperpolarization- 
A

i

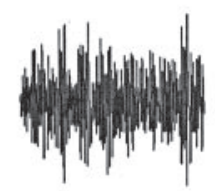

B

i

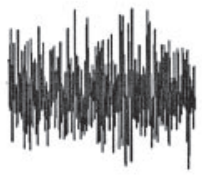

L
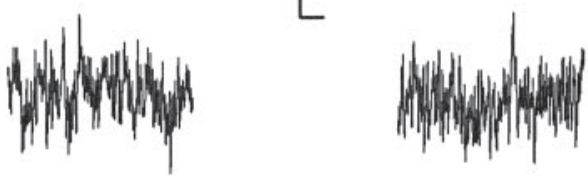

ii

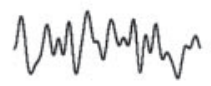

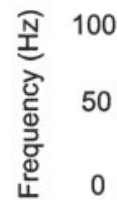

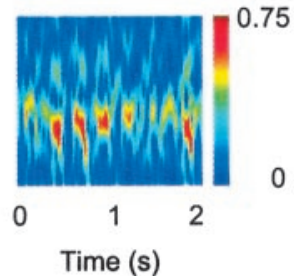

iii

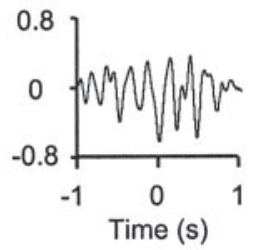

ii
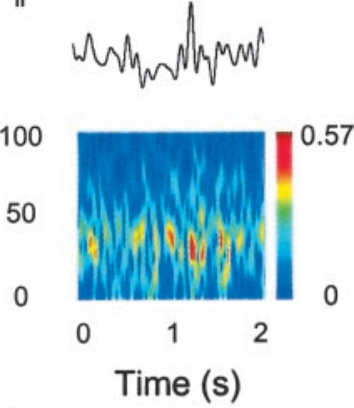

iii

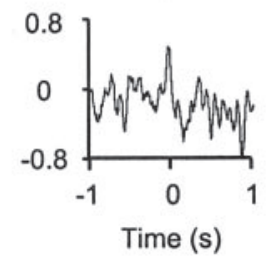

Figure 9. Blockade of $I_{\mathrm{h}}$ disrupts theta frequency modulation of field gamma oscillations and subthreshold membrane potential oscillations in stellate cells. $A$, Control data. $i$, Concurrent recordings of field from a layer II (top trace) and a layer II stellate neuron (middle trace) demonstrating power modulation of field gamma response coinciding with subthreshold slow membrane potential oscillations in stellate neurons. Bottom trace shows the same data from a stellate cell low-pass filtered at $12 \mathrm{~Hz}$. ii, Spectrogram of field gamma frequency activity illustrating quantal nature of the power in the gamma band. iii, Cross-correlogram of field data versus low-pass filtered stellate membrane potential data. $B$, Effects of $10 \mu \mathrm{m}$ ZD7288. $i$, Concurrent recordings of field from layer II (top trace) and a layer II stellate neuron (middle trace) demonstrating the disruption of power modulation of field gamma response concurrently with disruption of the subthreshold slow membrane potential oscillations in stellate neurons. Bottom trace shows the same data from a stellate cell low-pass filtered at $12 \mathrm{~Hz}$. ii, Spectrogram of field gamma frequency activity illustrating disrupted quantal nature of the power in the gamma band. iii, Cross-correlogram of field data versus low-pass filtered stellate cell membrane potential data. Calibration: Ai, Bi, $20 \mu \mathrm{V}$ (top traces), $2 \mathrm{mV}$ (bottom traces), $250 \mathrm{msec}$.

activated current $\left(I_{\mathrm{h}}\right)$, which is blocked by ZD7288. Bath application of ZD7288 had no significant effect on overall field gamma power measured as area (control, $379.8 \pm 134.9 \mu \mathrm{V}^{2} \mathrm{sec}^{-1}$; ZD7288, 324.3 $\left.\pm 121.0 \mu \mathrm{V}^{2} \mathrm{sec}^{-1} ; p>0.1 ; n=8\right)$. However, no rhythmic pattern of modulation of field gamma frequency was seen in the presence of this drug (Fig. 9). Cross-correlograms of subthreshold stellate cell activity and the field oscillations showed a significant reduction in central peak amplitude (control, $-0.05 \pm 0.00 ;$ ZD7288, $-0.02 \pm 0.01 ; p<0.05 ; n=5$ ) and a significant reduction in the peak frequency of stellate cell membrane potential oscillations from $3.2 \mathrm{~Hz}$ (above) to $2.0 \pm 0.2 \mathrm{~Hz}$ $(p<0.05)$, with a considerable broadening of the spectral peak within the theta frequency range.

\section{Discussion}

The entorhinal cortex plays a pivotal role in transferring information to and from the neocortex and the limbic regions of the brain (Fernandez et al., 1999; Fell et al., 2001). It has been proposed to act as a major associational area, taking information from many neocortical areas (Van Hoesen, 1982; Amaral and Witter, 1989; Witter et al., 1989). Associating activity from spatially distant brain regions in a single, separate region may be seen as an extension of the binding hypothesis for associating activity in areas coding for separate features of a sensory object. The role of rhythmogenesis (particularly at gamma frequencies) may therefore be seen as a critical tool used by the entorhinal cortex to temporally organize multiple inputs of diffuse spatial origin. Different forms of gamma frequency network activity have different properties relevant to the temporal organization of local and spatially distributed firing patterns (Whittington et al., 2000). Thus, it is important to understand the mechanisms used by the entorhinal cortex to generate gamma frequency oscillations.

Gamma frequency rhythmogenesis in the hippocampal formation is becoming better understood and provides a reference point with which to compare entorhinal rhythms. The present data demonstrated that, at least superficially, the medial entorhinal cortex can generate persistent field gamma rhythms in a manner similar to the hippocampus in the presence of kainate receptor activation. The lateral entorhinal cortex did not respond in such a manner in the slice as in whole-brain studies (van Der Linden et al., 1999; Dickson et al., 2000b). There is a lack of evidence for gross anatomical and cytoarchitectonic differences between the lateral and medial entorhinal cortex (van Der Linden et al., 1999). However, the lateral entorhinal cortex does receive afferent input from different sources to the medial entorhinal cortex (Kosel et al., 1982; Swanson and Köhler 1986), further providing evidence for a functional difference between the two regions.

In vivo and whole-brain studies also demonstrated a marked $180^{\circ}$ phase change between laminas II and III in the mEC. This observation was replicated in the slice preparation here but could not be ascribed to two independent, anti-phase, gamma generators. Instead, principal neurons on either side of the phase reversal point received temporally identical patterns of gamma frequency IPSPs. These data suggested that the phase reversal seen in field recordings may represent a source-sink interaction. The main polar neurons in the $\mathrm{mEC}$ are the pyramidal neurons found predominantly in layer III. Spatially discrete, perisomatic and proximal apical dendritic synaptic inputs from interneurons onto these cells, as seen for hippocampal pyramids (Papp et al., 2001), would be expected to generate the field phase relationship seen here and in the in vivo-whole-brain situation.

In the hippocampus, two main subtypes of GABA-dependent gamma frequency network activity can be seen experimentally. The first subtype, interneuron network gamma (ING), is seen transiently in response to brief periods of direct excitation of populations of interneurons (Whittington et al., 1995). It requires no phasic excitatory input from principal cells and generates a gamma frequency network output on the basis of the kinetics of interneuron-interneuron IPSPs. As such, it is exquisitely sensitive, in terms of frequency, to barbiturates and requires no gap junctional communication for local generation (Traub et al., 2001). The second type, pyramidal-interneuron network gamma (PING), is seen persistently and does require phasic synaptic excitation of interneurons via AMPA receptors (Fisahn et al., 1998; Traub et al., 2000; Hormuzdi et al., 2001). It is less sensitive to 
barbiturates, in terms of frequency, and requires gap junctional communication in conditions in which individual principal cell firing rates are much lower than population frequency. The gamma oscillations seen in the mEC correspond more closely to PING than to ING: they require AMPA receptors and gap junctions, and the frequency is altered only a little (but significantly) by barbiturates. However, the spike rates for layer III pyramidal cells was higher than that seen in CA3 and CA1 pyramids. Despite this, the frequency of EPSPs invading fast spiking interneurons in the superficial entorhinal cortex was significantly lower than the spike frequency in these cells. The interneurons generated an output that matched the field gamma frequency, suggesting that some action potentials were generated as a consequence of tonic excitatory drive and not through the phasic drive from population EPSPs, a situation reminiscent of ING models in the hippocampal formation.

Field theta oscillations are a prominent feature of in vivo recordings from the entorhinal cortex. However, these rhythms are thought to arise mainly from inputs from the medial septum/ diagonal band (Mitchell et al., 1982; Dickson et al., 1994; Jeffery et al., 1995; Leranth et al., 1999), a structure absent from the slices used in the present work. However, strong-amplitude modulation of field gamma rhythms was seen at theta frequencies, suggesting that the EC can generate theta frequency oscillations intrinsically. The most likely source for this modulation comes from stellate cells in the superficial layers. No theta modulation was seen in the deep layers (Fig. 8), and stellate cells have been proposed to generate theta frequency oscillations both alone, as a consequence of intrinsic conductances, and as a network of neurons coupled by recurrent excitation (Haas and White, 2002).

Intrinsic conductances such as $I_{\mathrm{h}}$ have been shown to be involved in generating theta frequency outputs from theta generating interneurons in the hippocampus (Gillies et al., 2002), and stellate cells express large amounts of this conductance (Alonso and Llinás, 1989; Alonso and Llinás, 1993; White et al., 1995; Dickson et al., 2000a). Blockade of $I_{\mathrm{h}}$ with ZD7266 significantly disrupted both subthreshold stellate cell theta rhythms and the theta frequency modulation of field gamma amplitude. These data suggest that stellate cells may modulate gamma frequency activity in the superficial EC, in addition to providing a population theta frequency output to the hippocampal formation via the perforant path (Holsheimer et al., 1983; Boeijinga and Lopes da Silva, 1988; Heynen and Bilkey, 1994; Bragin et al., 1995; Charpak et al., 1995; Chrobak and Buzsáki, 1998).

In summary, the medial entorhinal cortex in vitro generates persistent gamma oscillations in a manner similar to that seen in the cornu ammonis. Differential involvement of pyramidal neurons and stellate cells (in terms of mean firing frequency) suggests different patterns of input to the hippocampus via the temporoammonic and perforant pathways during gamma oscillations in vivo. The greater frequency of action potential generation in pyramidal cells compared with stellate cells suggests that persistent entorhinal gamma frequency oscillations exert more of an active influence on cornu ammonis subfields directly as opposed to via the dentate gyrus. The similarities in mechanisms used by the hippocampal cornu ammonis and superficial mEC to generate gamma frequency population oscillations may facilitate the temporal organization of information passing along this axis.

\section{References}

Alonso A, Llinás RR (1989) Subthreshold $\mathrm{Na}^{+}$-dependent theta-like rhythmicity in stellate cells of entorhinal cortex layer II. Nature 342:175-177. Alonso A, Llinás RR (1993) Differential electroresponsiveness of stellate and pyramidal-like cells of medial entorhinal cortex layer II. J Neurophysiol 70:128-143.

Amaral DG, Witter MP (1989) The three-dimensional organization of the hippocampal formation: a review of anatomical data. Neuroscience 31:571-591.

Barth DS, MacDonald KD (1996) Thalamic modulation of high-frequency oscillating potentials in auditory cortex. Nature 383:78-81.

Beckmann H, Senitz D (2002) Developmental malformations in cerebral structures in "endogenous psychoses." J Neural Transm 109:421-431.

Behr J, Heinemann U, Mody I (2001) Kindling induces transient NMDA receptor-mediated facilitation of high-frequency input in the rat dentate gyrus. J Neurophysiol 85:2195-2202.

Boeijinga PH, Lopes da Silva FH (1988) Differential distribution of beta and theta EEG activity in the entorhinal cortex of the cat. Brain Res 448:272-286.

Braak H, Braak E (1991) Neuropathological stageing of Alzheimer-related changes. Acta Neuropathol (Berl) 82:239-259.

Bragin A, Jando G, Nadasdy Z, Hetke J, Wise K, Buzsáki G (1995) Gamma (40-100 Hz) oscillation in the hippocampus of the behaving rat. J Neurosci 15:47-60.

Buhl EH, Tamas G, Fisahn A (1998) Cholinergic activation and tonic excitation induce persistent gamma oscillations in mouse somatosensory cortex in vitro. J Physiol (Lond) 513:117-126.

Burwell RD, Witter MP (2002) Basic anatomy of the parahippocampal region in monkeys and rats. In: The parahippocampal region: organization and role in cognitive function, Ed 1. Oxford: Oxford UP.

Charpak S, Pare D, Llinás R (1995) The entorhinal cortex entrains fast CA1 hippocampal oscillations in the anaesthetized guinea-pig: role of the monosynaptic component of the perforant path. Eur J Neurosci 7:1548-1557.

Chrobak JJ, Buzsáki G (1998) Gamma oscillations in the entorhinal cortex of the freely behaving rat. J Neurosci 18:388-398.

Cunningham MO, Davies CH, Buhl EH, Whittington MA (2002a) Gamma oscillations induced by tonic excitation in the medial entorhinal cortex in vitro. FENS Abstr 1:A146.1.

Cunningham MO, Davies CH, Buhl EH, Whittington MA (2002b) Characterisation of kainate induced gamma oscillations in the entorhinal cortex in vitro. J Physiol (Lond) 544:C53.

Dickson CT, Alonso A (1997) Muscarinic induction of synchronous population activity in the entorhinal cortex. J Neurosci 17:6729-6744.

Dickson CT, Trepel C, Bland BH (1994) Extrinsic modulation of theta field activity in the entorhinal cortex of the anesthetized rat. Hippocampus 4:37-51.

Dickson CT, Magistretti J, Shalinsky MH, Fransen E, Hasselmo ME, Alonso A (2000a) Properties and role of $\mathrm{I}(\mathrm{h})$ in the pacing of subthreshold oscillations in entorhinal cortex layer II neurons. J Neurophysiol 83:2562-2579.

Dickson CT, Biella G, de Curtis M (2000b) Evidence for spatial modules mediated by temporal synchronization of carbachol-induced gamma rhythm in medial entorhinal cortex. J Neurosci 20:7846-7854.

Fell J, Klaver P, Lehnertz K, Grunwald T, Schaller C, Elger CE, Fernandez G (2001) Human memory formation is accompanied by rhinalhippocampal coupling and decoupling. Nat Neuroscience 4:1259-1264.

Fernandez G, Effern A, Grunwald T, Pezer N, Lehnertz K, Dumpelmann M, Van Roost D, Elger CE (1999) Real-time tracking of memory formation in the human rhinal cortex and hippocampus. Science 285:1582-1585.

Fisahn A (1999) An investigation into cortical gamma frequency oscillations in vitro. $\mathrm{PhD}$ thesis, University of Oxford.

Fisahn A, Pike FG, Buhl EH, Paulsen O (1998) Cholinergic induction of network oscillations at $40 \mathrm{~Hz}$ in the hippocampus in vitro. Nature 394:186-189.

Gillies MJ, Traub RD, LeBeasu FE, Davies CH, Gloveli T, Buhl EH, Whittington MA (2002) A model of atropine-resistant theta oscillations in the rat hippocampal area CA1. J Physiol (Lond) 543:779-793.

Gloveli T, Egorov AV, Schmitz D, Heinemann U, Muller W (1999) Carbachol-induced changes in excitability and $\left[\mathrm{Ca}^{2+}\right]_{\mathrm{i}}$ signalling in projection cells of medial entorhinal cortex layers II and III. Eur J Neurosci 11:3626-3636.

Gray CM, Konig P, Engel AK, Singer W (1989) Oscillatory responses in cat visual cortex exhibit inter-columnar synchronization which reflects global stimulus properties. Nature 338:334-337.

Haas JS, White JA (2002) Frequency selectivity of layer II stellate cells in the medial entorhinal cortex. J Neurophysiol 88:2422-2429. 
Hájos N, Katona I, Naiem SS, MacKie K, Ledent C, Mody I, Freund TF (2000) Cannabinoids inhibit hippocampal GABAergic transmission and network oscillations. Eur J Neurosci 12:3239-3249.

Harris E, Witter MP, Weinstein G, Stewart M (2001) Intrinsic connectivity of the rat subiculum. I. Dendritic morphology and patterns of axonal arborization by pyramidal neurons. J Comp Neurol 435:490-505.

Heynen AJ, Bilkey DK (1994) Effects of perforant path procaine on hippocampal type 2 rhythmical slow-wave activity (theta) in the urethaneanesthetized rat. Hippocampus 4:683-695.

Hirai N, Uchida S, Maehara T, Okubo Y, Shimizu H (1999) Enhanced gamma $(30-150 \mathrm{~Hz})$ frequency in the human medial temporal lobe. Neuroscience 90:1149-1155.

Holsheimer J, Stok CJ, Lopes da Silva FH (1983) Theta rhythm related hippocampal cell discharges in the urethane anaesthetized rat: evidence for a predominant entorhinal input. Electroencephalogr Clin Neurophysiol 55:464-467.

Hormuzdi SG, Pais I, LeBeau FE, Towers SK, Rozov A, Buhl EH, Whittington MA, Monyer H (2001) Impaired electrical signaling disrupts gamma frequency oscillations in connexin 36-deficient mice. Neuron 31:487-495.

Hyman BT, Van Horsen GW, Damasio AR, Barnes CL (1984) Alzheimer's disease: cell-specific pathology isolates the hippocampal formation. Science 225:1168-1170.

Jeffery KJ, Donnett JG, O’Keefe J (1995) Medial septal control of thetacorrelated unit firing in the entorhinal cortex of awake rats. NeuroReport $6: 2166-2170$

Jones RSG (1994) Synaptic and intrinsic properties of neurones of origin of the perforant path in layer II of the rat entorhinal cortex in vitro. Hippocampus 4:335-353

Kosel KC, Van Hoesen GW, Rosene DL (1982) Non-hippocampal cortical projections from the entorhinal cortex in the rat and rhesus monkey. Brain Res 244:201-213.

Leranth C, Carpi D, Buzsaki G, Kiss J (1999) The entorhino-septosupramammillary nucleus connection in the rat: morphological basis of a feedback mechanism regulating hippocampal theta rhythm. Neuroscience 88:701-718.

Li P, Wilding TJ, Kim SJ, Calejesan AA, Huettner JE, Zhuo M (1999) Kainate-receptor-mediated sensory synaptic transmission in mammalian spinal cord. Nature 397:161-164.

Mitchell SJ, Rawlins JN, Steward O, Olton DS (1982) Medial septal area lesions disrupt theta rhythm and cholinergic staining in medial entorhinal cortex and produce impaired radial arm maze behavior in rats. J Neurosci 2:292-302.

Murthy VN, Fetz EE (1996) Oscillatory activity in sensorimotor cortex of awake monkeys: synchronization of local field potentials and relation to behavior. J Neurophysiol 76:3949-3967.

Naber PA, Lopes da Silva FH, Witter MP (2001) Reciprocal connections between the entorhinal cortex and hippocampal fields CA1 and the subiculum are in register with the projections from CA1 to the subiculum. Hippocampus 11:99-104.

Papp E, Leinekugel X, Henze DA, Lee J, Buzsaki G (2001) The apical shaft of CA1 pyramidal cells is under GABAergic interneuronal control. Neuroscience 102:715-721.

Roelfsema PR, Engel AK, Konig P, Singer W (1997) Visuomotor integration is associated with zero time-lag synchronization among cortical areas. Nature 385:157-161.

Singer W, Gray CM (1995) Visual feature integration and the temporal correlation hypothesis. Annu Rev Neurosci 18:555-586.

Steward O, Scoville SA (1976) Cells of origin of entorhinal cortical afferents to the hippocampus and fascia dentata of the rat. J Comp Neurol 169:347-370.

Swanson LW, Köhler C (1986) Anatomical evidence for direct projections from the entorhinal area to the entire cortical mantle in the rat. J Neurosci 6:3010-3023

Traub RD, Bibbig A, Fisahn A, LeBeau FE, Whittington MA, Buhl EH (2000) A model of gamma-frequency network oscillations induced in the rat CA3 region by carbachol in vitro. Eur J Neurosci 12:4093-4106.

Traub RD, Kopell N, Bibbig A, Buhl EH, LeBeau FE, Whittington MA (2001) Gap junctions between interneuron dendrites can enhance synchrony of gamma oscillations in distributed networks. J Neurosci 21:9478-9486.

Uchida S, Maehara T, Hirai N, Okubo Y, Shimizu H (2001) Cortical oscillations in human medial temporal lobe during wakefulness and all-night sleep. Brain Res 891:7-19.

Valera F, Lachaux JP, Rodriguez E, Martinerie J (2001) The brainweb: phase synchronization and large scale integration. Nat Rev Neurosci 2:220-239.

van Der Linden S, Lopes de Silva FH (1998) Comparison of the electrophysiological and morphology of layers III and II neurons of the rat media entorhinal cortex in vitro. Eur J Neurosci 10:1479-1489.

van Der Linden S, Panzica F, de Curtis M (1999) Carbachol induces fast oscillations in the medial but not in the lateral entorhinal cortex of the isolated guinea pig brain. J Neurophysiol 82:2441-2450.

Van Hoesen (1982) The parahippocampal gyrus. New observations regarding its coritcal connections in the monkey. Trends Neurosci 5:345-350.

Van Hoesen GW, Hyman BT, Damasio AR (1986) Cell-specific pathology in neural systems of the temporal lobe in Alzheimer's disease. Prog Brain Res 70:321-335.

Van Hoesen GW, Hyman BT, Damasio AR (1991) Entorhinal cortex pathology in Alzheimer's disease. Hippocampus 1:1-8.

White JA, Budde T, Kay AR (1995) A bifurcation analysis of neuronal subthreshold oscillations. Biophys J 69:1203-1217.

Witter MP, Groenewegen HJ (1984) Laminar origin and septotemporal distribution of entorhinal and perirhinal projections to the hippocampus in the cat. J Comp Neurol 224:371-385.

Witter MP, Room P, Groenewegen HJ, Lohman AH (1986) Connections of the parahippocampal cortex in the rat. V. Intrinsic connections; comments on input/output connections with the hippocampus. J Comp Neurol 252:78-94.

Witter MP, Groenewegen HJ, Lopes da Silva FH, Lohman AH (1989) Functional organization of the extrinsic and intrinsic circuitry of the parahippocampal region. Prog Neurobiol 33:161-253.

Whittington MA, Traub RD, Jefferys JG (1995) Synchronized oscillations in interneuron networks driven by metabotropic glutamate receptor activation. Nature 373:612-615.

Whittington MA, Traub RD, Kopell N, Ermentrout B, Buhl EH (2000) Inhibition-based rhythms: experimental and mathematical observations on network dynamics. Int J Psychophysiol 38:315-336. 